\title{
Gynecologic oncology fellowship in Indonesia
}

\author{
Brahmana Askandar Tjokroprawiro 다 , Surabaya, Indonesia
}

Indonesia is the fourth most populous country globally, with a population of about 270 million according to a World Bank report published in 2019. The country consists of approximately 17000 islands, and it is difficult to centralize gynecologic cancer treatment. In many areas, the infrastructure is not well developed, making it difficult to refer patients with gynecologic cancer from villages or small cities to tertiary hospitals. Moreover, the socioeconomic condition of patients, such as the lack of money to cover transportation and expenses for daily living needs, prevents them from accessing tertiary hospital in large cities despite a referral.

Cervical cancer is the most significant gynecological cancer in Indonesia, followed by ovarian and endometrial cancers. Most patients with cervical cancer are diagnosed at an advanced stage and require radiotherapy. Limited radiotherapy centers have worsened the prognosis of cervical cancer in Indonesia. In 2018, there were only 44 radiotherapy centers in Indonesia

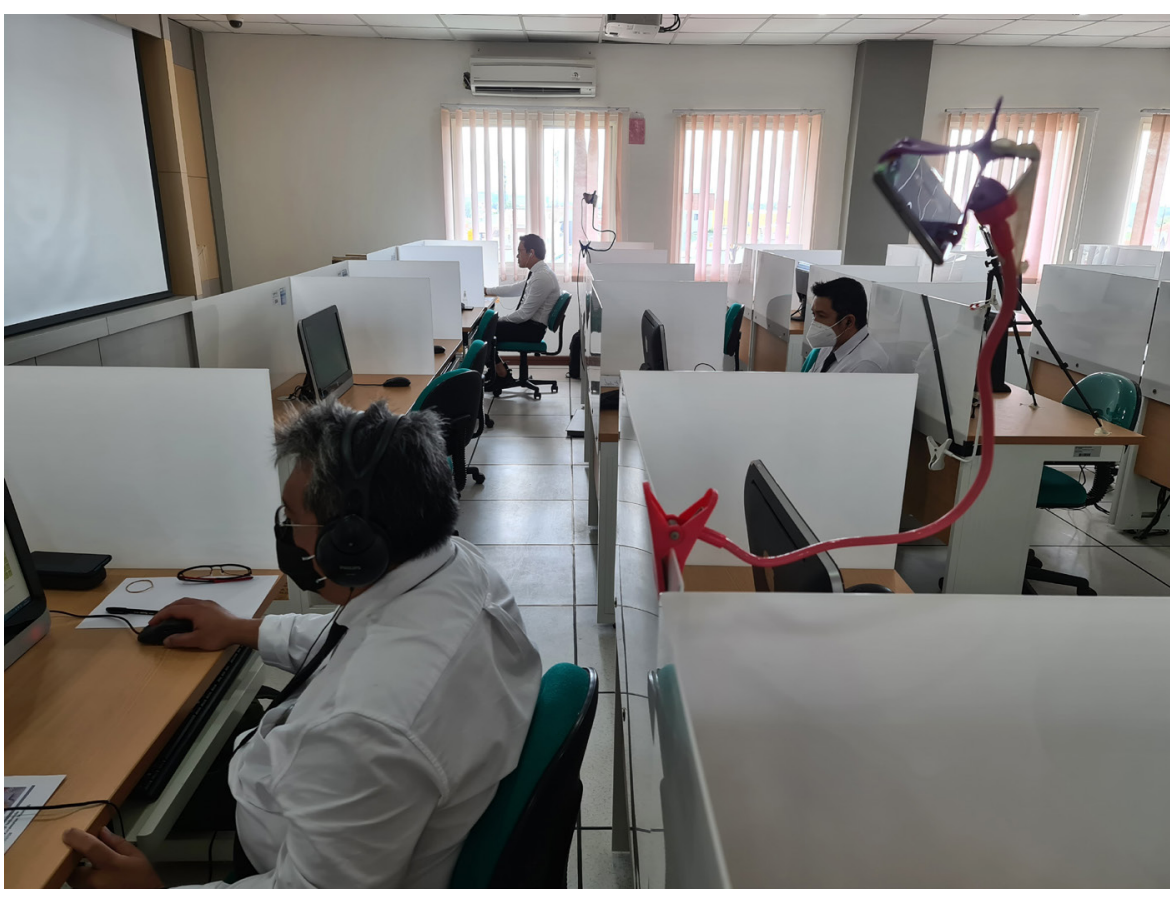

Figure 2 An online national board test at the end of the gynecologic oncology fellowship during pandemic. A fellow passing the test becomes a certified gynecologic oncologist.

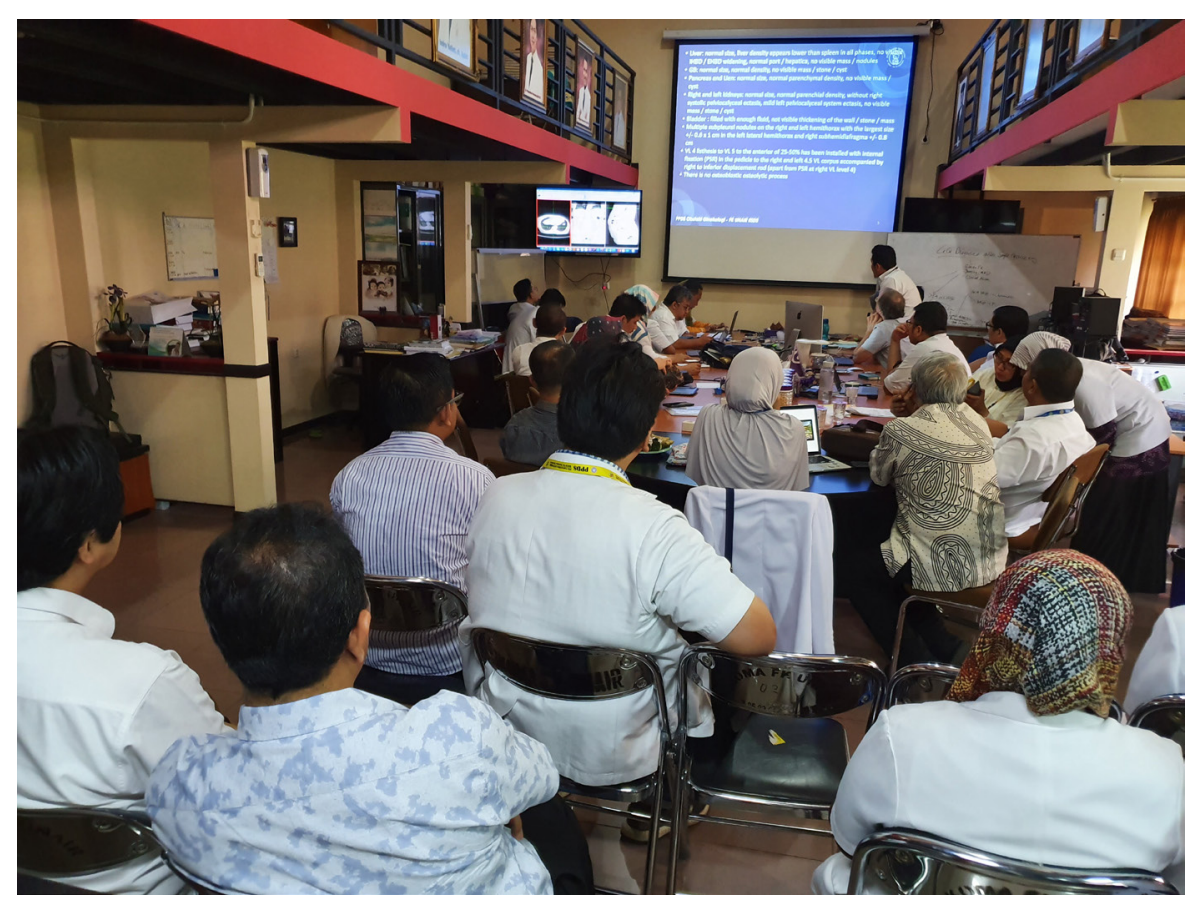

Figure 1 A weekly gynecologic oncology tumor board in every training center. The fellows involved in the presentation and discussion of the case. with 66 machines in total (49 linear accelerators, 16 cobalt, and one tomotherapy system). Radiotherapy is available in only 15 of 34 provinces in Indonesia. One of the main problems of gynecologic cancer treatment in Indonesia is the number of gynecologic oncologists. As of 2020, there were only 109 gynecologic oncologists in Indonesia distributed unevenly across the country; most were based on Java Island. The population of Java Island is about 124 million with 66 gynecologic oncologists in total, of whom 25 are in Jakarta, Indonesia's capital. Nine provinces do not have gynecological oncologists. Eastern Indonesia has a population of approximately 40 million people and has only 14 gynecologic oncologists.

The Indonesian Society of Gynecologic Oncologists (INASGO) working together with three universities in Indonesia-The University of Indonesia in Jakarta, The University of Padjajaran in Bandung, and the University of Airlangga in Surabaya_-offers a fellowship to gynecologic oncologists. 


\section{Corners of the world}

The role of INASGO is to create a national curriculum for the gynecologic oncology fellowship, conduct a national board test at the end of the training, register gynecologic oncologists, and re-certify them periodically every 5 years. INASGO intends to boost the number of gynecologic oncologists in Indonesia through this program. According to the program directives, the gynecologic oncology fellowship must be university-based and in collaboration with an academic hospital. All gynecologists must first apply through the university to the fellowship. Following this, INASGO and the university perform screening and select a candidate. Each training center accepts two fellows every semester. The duration of the fellowship is 2 years. The fellowship involves studying and working in an academic hospital. The candidates work without payment and must pay a tuition fee to the university every semester. A prospective partnering institute must fulfill several criteria to become a training center for gynecologic oncology. This includes having one professor, one $\mathrm{PhD}$, and six gynecologic oncologists in the division of gynecologic oncology in an academic hospital. Increasing the number of gynecologic oncologists in Indonesia is difficult. INASGO strives to improve this by increasing the number of training centers around the country.

Correspondence to Dr Brahmana Askandar Tjokroprawiro, Department of Obstetrics and Gynecology, Universitas Airlangga Fakultas Kedokteran, Surabaya, Indonesia; brahmanaaskandar@gmail.com

Contributors BAT was solely responsible for the manuscript writing and editing.
Funding The authors have not declared a specific grant for this research from any funding agency in the public, commercial or not-for-profit sectors.

Competing interests None declared.

Patient consent for publication Not required.

Provenance and peer review Not commissioned; externally peer reviewed.

(C) IGCS and ESG0 2021. No commercial re-use. See rights and permissions. Published by BMJ.

D) Check for updates

To cite Tjokroprawiro BA. Int J Gynecol Cancer 2021;31:1085-1086.

Accepted 4 January 2021

Published Online First 13 January 2021

Int J Gynecol Cancer 2021;31:1085-1086. doi:10.1136/ijgc-2020-002354

ORCID iD

Brahmana Askandar Tjokroprawiro http://orcid.org/ 0000-0003-1658-3477 